\title{
O EFEITO PRIMING E OS OLHOS DO DIREITO: UMA ANÁLISE SOBRE A NECESSIDADE DA ATENÇÃO DA COMUNIDADE JURÍDICA ÀS TÉCNICAS DE PRÉ-ATIVAÇÃO
}

\author{
Rômulo Ventura de Oliveira Lima Chaves ${ }^{1}$ \\ Anamaria Pereira Morais ${ }^{2}$
}

RESUMO: Os estudos desenvolvidos pela neurociência e outros ramos afins acerca dos processos cognitivos inconsciente possibilita que sejam identificados fenômenos que possuem grande impacto no cotidiano, mas que ocorrem de maneira totalmente despercebida. A partir do seu conhecimento e da possibilidade do seu manejo, surge a necessidade do Direito voltar seu olhar para essa manipulação para evitar que direitos fundamentais individuais e sociais sejam aviltados. Este trabalho tem o propósito de apresentar um desses fenômenos, o efeito priming, e a importância da comunidade jurídica analisá-lo adequadamente, a fim de evitar que os direitos passem a ser transgredidos à revelia da consciência.

PALAVRAS-CHAVE: Neurodireito. Efeito priming. Estudo interdisciplinar. Processos cognitivos inconscientes. Direitos fundamentais.

\section{THE PRIMING EFFECT AND THE EYES OF LAW: AN ANALYSIS ON THE NEED FOR LEGAL COMMUNITY ATTENTION TO PRE-ACTIVATION TECHNIQUES}

\begin{abstract}
The studies carried out by neuroscience and other related branches about the unconscious cognitive processes make it possible to identify phenomena that have a great impact on daily life, but that occur in a totally unnoticed way. From its knowledge and the possibility of its management, there is a need for the Law to turn its attention to this manipulation in order to avoid that individual and social fundamental rights are degraded. This paper has the purpose of presenting one of these phenomena, the priming effect, and the importance of the legal community to analyze it properly, in order to prevent the rights from being violated by default.
\end{abstract}

KEYWORDS: Neurodirection. Priming effect. Interdisciplinary study. Unconscious cognitive processes. Fundamental rights.

\section{INTRODUÇÃO}

\footnotetext{
${ }^{1}$ Mestrando em Direito, com área de concentração em Constituição, Sociedade e Pensamento Jurídico, na Universidade Federal do Ceará- UFC (2020-2022), bolsista da FUNCAP, pesquisador do Núcleo de Pesquisa em Interpretação e Decisão Judicial- NUPID, especialista em Direito Processual Civil (2016-2017), bacharel em direito na Unichristus (2011-2015), Fortaleza-Ce.

2 Mestranda em Direito, área de concentração em Constituição, Sociedade e Pensamento Jurídico, na Universidade Federal do Ceará- UFC (2020-2022), especialista em Direito Constitucional (2015-2016), bacharel em Direito na Unichristus, Fortaleza- Ce (2010-2014). Advogada.
} 
A partir do conhecimento de que o cérebro é o órgão que controla todo o corpo e que é dele que surgem todos os pensamentos, os desejos, as convicções, as razões, e que é nele que ficam guardadas todas as memórias e todo o conhecimento adquirido ao longo da vida, é natural que se passe a ter um grande interesse em conhecê-lo cada mais, pois a partir dessa constatação, conhecer detalhadamente o cérebro significa conhecer detalhadamente quem é o ser humano.

Diante da complexa conjuntura de atividades desempenhadas por este órgão, a ciência se divide em vários ramos para explorá-lo de maneira mais especializada, surgindo ao longo do tempo novos ramos à medida que os estudos apresentam descobertas que possuem dimensão suficiente para justificar a criação de uma nova área de pesquisa. Uma vasta e promissora área é o estudo do comportamento humano que, dentre suas várias vertentes, presta-se a estudar a forma como os indivíduos tomam suas decisões. Não raramente esses estudos são iniciados por insights tidos pelos pesquisadores ao observar o outro ou, até mesmo, a si, o que o demonstra o quão inerentes e constantes aos indivíduos são os fatos estudados por essa área, logo, o quão úteis e benéficas podem ser as suas conclusões - desde que usadas adequadamente.

O desenvolvimento desses estudos demonstra que nem todas as decisões são tomadas de maneira racional e consciente, mas em grande parte as atividades cognitivas são realizadas de maneira automática e inconsciente, ou seja, elas se iniciam involuntariamente e o seu desenvolvimento ocorre à revelia da consciência. Em outras palavras, o cérebro processa diversas informações sem que o indivíduo saiba que elas estão sendo processadas. No entanto, esse tipo de cognição inconsciente, apesar de ser uma função essencial para que o ser humano tenha a capacidade de realizar as atividades que desempenha diariamente, também comete enviesamento ou erros de julgamento que podem ser - não necessariamente são - nocivos.

Um desses enviesamentos é chamado de efeito priming ou efeito de pré-ativação, que se caracteriza pela influência que um estímulo apresentado a um indivíduo possui em modificar a resposta a um segundo estímulo apresentado posteriormente, sem que exista a consciência do indivíduo sobre tal influência (BARGH, 2006). Em outras palavras, a exposição de um indivíduo a um estímulo pode influenciar as suas motivações, avaliações, decisões ou seus julgamentos no momento subsequente, sem que ele tenha a consciência de que a sua ação foi influenciada. 
Apesar de se tratar de fenômeno que sempre existiu, por ser inerente a forma como o sistema cognitivo humano funciona, a partir da descoberta da sua existência e do seu mecanismo de desenvolvimento se passa a ter uma predisposição a criar técnicas para se evitar os efeitos nocivos, bem como técnicas para utilizá-los com o fim de torná-los facilitadores de algumas atividades, sendo atualmente bastante conhecida a utilização do priming em técnicas de negociação entre empresas ou entre empresas e o consumidores (CIALDINI, 2017).

Como consequência dessas descobertas, passou a existir a necessidade de analisar os processos decisórios a partir de novos parâmetros, os quais proporcionaram a abertura para estudos de natureza cada vez mais multidisciplinares, visto que a compreensão dos fenômenos que aqui são tratados surge de análises teóricas e pesquisas empíricas de diferentes ramos da ciência. É nesse cenário que surge a Economia Comportamental, tendo desde sua gênese um corpo interdisciplinar, concentrando estudos da neurociência, da psicologia, da sociologia, que visam a análise dos fatores psicológicos, emocionais e cognitivos relativos aos limites da racionalidade e como isso impacta na tomada de decisões. A importância desses trabalhos é demonstrada pelo fato de, apesar de ainda ser uma ciência nova, já ter proporcionado dois prêmios Nobel de economia nos últimos vinte anos, sendo Richard Thaler em 2017 e Daniel Kahneman em 2002, que, ressalta-se, tem formação em psicologia, o que reforça a interação e a relevância dessa interdisciplinaridade. Afora esses, Herbert Simon, por alguns considerado o pai do behaviorismo, também foi destinatário do prêmio em 1978 por ter desenvolvido uma das pioneiras contribuições ao estudo do processo de adoção de decisões nas organizações econômicas.

A dimensão e a robustez do avanço dessas pesquisas que modificaram a forma como o processo cognitivo é visto - em especial a forma como as decisões são realizadas -, refutando a ideia dominante do homo economicus e demonstrando que as escolhas são realizadas em grande parte por influência de elementos que estão abaixo da linha da consciência, faz surgir o questionamento se o Direito também não deve ser integrado aos estudos interdisciplinares para analisar se deverá haver modificação na legislação vigente de modo a se adequar aos novos paradigmas apresentados, se tais descobertas não representam substrato suficiente para modificar a forma como o sistema judicial atualmente é composto, ou se é necessária uma maior atenção por parte da comunidade jurídica a esses novos 
institutos, visto terem a capacidade de se tornarem instrumentos de atos que podem se tornar fatos jurídicos.

No entanto, para a consecução dessas respostas é necessário um amplo e dedicado trabalho que tenha por base um conhecimento de conceitos de todos os institutos que se relacionam à matéria, o que não se verifica em escala adequada dentro da comunidade acadêmica jurídica.

Diante dessa deficiência, este trabalho tem o propósito de apresentar de maneira propedêutica a matéria com o fim de alertar a necessidade de uma inclinação a essa temática por parte do Direito, servindo como um material de introdução aos estudos teóricos e práticos desenvolvidos na área da neuropsicologia e da economia comportamental.

Para tanto, foi realizada uma pesquisa bibliográfica na literatura nacional e estrangeira atinente à economia comportamental e à neurociência voltada ao estudo dos processos cognitivos humanos e ao efeito priming, de modo que pudesse ser realizado um paralelo com a legislativa brasileira contemporânea.

\section{A MENTE INCONSCIENTE: NÃO NOS CONHECEMOS TANTO QUANTO ACHAMOS QUE NOS CONHECEMOS}

Desde os séculos XVI e XVII, com o ascender de muitos conceitos que passaram a fazer parte da economia como uma ciência, surgiu a ideia do homo economicus, caracterizada pela crença de que o homem sempre toma suas decisões de maneira racional e visando os seus próprios interesses, não sendo parte integrante desse processo cognitivo as emoções ou qualquer interferência do meio que se esteja inserido. Essa visão é defendida, inclusive, na obra A Riqueza das Nações, de Adam Smith, na qual relata que o ser humano somente serviria a outro visando a troca de recompensas materiais, ignorando qualquer envolvimento emocional ou filantrópico.

A partir do final da primeira metade do século XX, estudos na área da neurociência e da economia passaram a demonstrar fortes evidências que o processo é mais complexo do que a simples análise racional do custo-benefício de determinada ação, mas é permeado de elementos emocionais e de fatores que não são identificados pela consciência, agindo do ocultismo da mente inconsciente. 
Em 1949, Hebb desenvolveu um modelo acerca das representações mentais denominado de assembleias celulares, na qual reconhecia que a mente possuía alguma independência acerca dos mandamentos conscientes. Argumenta que os pensamentos (representações mentais nas palavras do autor) poderiam ser ativados por elementos internos, a exemplo dos valores ou das motivações, como também externos (HEBB, 1950). Iniciava-se, com isso, a refutação da ideia de que as decisões derivariam exclusivamente da ponderação dos fatores objetivamente traçados como favoráveis ou desfavoráveis para o indivíduo.

Em 1974, o destacado artigo Julgamento sob Incerteza: Heurísticas e Vieses, Amos Tversky e Daniel Kahneman reforçam a ideia de que o homem possui uma habilidade cognitiva limitada, não sendo capaz de processar todas as informações que lhe são apresentadas, assim como demonstram que muitas decisões tomadas diariamente são baseadas em crenças relativas à probabilidade, fato esse que é facilmente constatado, segundo os autores, na quantidade de frases que são iniciadas com as expressões "acho que...", "as possibilidades são...”, “é pouco provável que...” (TVERSKY; KAHNEMAN, 1974).

Esta pesquisa foi desenvolvida a partir de uma visão antagônica a do homo economicus, pois demonstra que parte das decisões não são tomadas de maneira deliberada e completamente racionalizada, mas são meras intuições. Ademais, apresenta que as heurísticas são atalhos mentais que tem por finalidade diminuir o esforço e aumentar a velocidade de resposta, tornado o processo decisório mais eficaz. Para tanto, esses atalhos não consideram todas as informações disponíveis para que seja dada uma resposta com robusta fundamentação, sendo exatamente esse o motivo que o citado artigo demonstra que as heurísticas são causas sistemáticas de erros de julgamento, denominados de vieses.

Entretanto, à medida que o indivíduo se especializa em uma determinada atividade, menor o risco das intuições estarem erradas, visto que o aumento do número de informações adquiridas e a repetição da sua prática, provocam a consolidação da matéria na mente, passando a ser mais facilmente acessadas durante o processo de decisão. Contudo, são enfáticos os autores, ainda que uma pessoa seja especialista em determinado assunto, suas intuições ainda são passíveis de erros.

Portanto, as heurísticas são um mecanismo inato ao ser humano e responsáveis pela manutenção da capacidade de desempenho das mais variadas atividades desenvolvidas diariamente, permitindo que as decisões sejam tomadas em velocidades calculadas em milissegundos. Isso é o que demonstra o neuro-economista Antonio Rangel, pesquisador da 
Universidade de Pasadema, que em estudo desenvolvido em 2011 constatou que o cérebro pode realizar escolhas de qualidade, ou seja, que condizem com as preferências do indivíduo, em até 230ms (RANGEL; CHRISTOE; MILICA, 2011).

Kahneman, em sua obra Rápido e Devagar, classifica o sistema cognitivo como sendo bissistêmico, denominando de Sistema 1 o sistema que age de maneira rápida e automática, com pouco ou nenhum esforço e nenhuma percepção de controle voluntário, e de Sistema 2 o sistema que aloca atenção às atividades laboriosas, como a realização de cálculos complexos, atividades estas que criam no indivíduo uma sensação de experiência subjetiva de atividade, ou seja, o reconhecimento de que está realizando um exercício mental no momento que utiliza esse sistema. (KAHNEMAN, 2012).

São exemplos de atividades desempenhadas pelo Sistema 1 o reconhecimento do estado emocional de uma pessoa ao ver o seu rosto, a compreensão de frases simples na língua nativa ou em outra que se tenha domínio, dirigir um carro por uma rua vazia, dar um diagnóstico de uma doença simples a partir dos sintomas (no caso de médicos especializados na doença).

Para essas ações não há a necessidade de um aprofundamento de raciocínio, não gera no indivíduo a experiência subjetiva de que foi desempenhada uma atividade cerebral, elas simplesmente acontecem de maneira involuntária e com significativa velocidade, como já salientado no estudo de Antonio Rangel. Esse sistema possui a capacidade de ser continuamente aprimorado à medida que o indivíduo se especializa em uma atividade, o que pode ser exemplificado pela facilidade e rapidez que uma pessoa passa a reconhecer sentenças em línguas estrangeiras à medida que se aprimora nela, deixando de ser necessário um esforço em traduzir cada palavra e compreender a forma que elas estão dispostas, e passando a ser um ato absolutamente automático e instantâneo.

Por sua vez, o Sistema 2 pode ser exemplificado em ações tais como responder operações matemáticas complexas (caso não seja um matemático experiente), procurar uma pessoa usando fone de ouvido no meio de um pátio lotado, verificar a validade lógica de um argumento, verificar o melhor custo benefício entre dois produtos, produzir um artigo acadêmico, olhar as horas em um relógio analógico (para aqueles que têm costume de utilizar relógios digitais).

Em todas estas, há um reconhecido esforço mental por parte da pessoa que o desempenha e um notável tempo necessário para que ela seja concluída. Uma longa 
permanência nessa espécie de atividade faz com que a pessoa se sinta claramente cansada e passe a necessitar, a depender do caso, de um período de descanso para ter condições de continuá-la. Em decorrência do esforço despendido para essas atividades é que se torna difícil, senão impossível, desempenhar mais de uma ao mesmo tempo. Não parece ser razoável a possibilidade de se fazer uma baliza em uma vaga apertada enquanto escuta atentamente uma áudio-aula que está sendo reproduzida no som do carro.

Em contra partida, não exige muito esforço descer uma escadaria enquanto se tem uma conversa casual ao telefone celular, podendo-se inclusive incluir a essa ocasião uma rápida olhada no relógio de pulso para ver as horas.

Torna-se evidente a limitação da capacidade cognitiva e a adaptação cerebral em dividir as atividades entre os dois sistemas, revezando a predominância a depender da atividade desenvolvida, bem como em direcionar a atenção somente para o que é considerado importante, ignorando outros elementos que ocorrem no mesmo ambiente. Kahneman exemplifica tal afirmação ao se referir ao experimento feito por Christopher Chabris e Daniel Simons apresentado no livro O Gorila Invisível. O experimento constituiu-se em pedir que expectadores assistam um curta-metragem em que são exibidos dois times de basquete, um vestido de branco e outro de preto. Cada time fica trocando passes entre si, mas pela proximidade dos jogadores, era necessário o emprego de concentração para não confundir o passe de um time com o de outro. Os expectadores são orientados a contar o número de passes dados pelo time de branco por um determinado período. No meio do vídeo uma mulher vestida de gorila atravessa a quadra, bate no peito e desaparece depois de nove segundos. $\mathrm{O}$ vídeo foi visto por milhares de pessoas e somente cerca de metade viu o gorila. A instrução de observar os passes da bola e, em especial, contar somente os passes de um time, ignorando os do outro, fez com que toda a capacidade cognitiva fosse direcionada para esta atividade.

A função de ver e se orientar de maneira automática é do Sistema 1, mas ele depende de alocação de alguma atenção ao estímulo relevante, o que não ocorria na ocasião, pois toda a capacidade cognitiva estava alocada na contagem dos passes. Com isso, Kahneman conclui que dois importantes fatos podem ser constatados acerca da mente: "podemos ficar cegos para o óbvio, e também somos cegos para a nossa própria cegueira" (KAHNEMAN, 2012). Não é possível captar todas as informações que são apresentadas no meio em que se está inserido, e por isso, a atenção é alocada no que é considerado importante. No entanto, dificilmente ocorre o reconhecimento dessa realidade limitadora do homem. 
Os dois sistemas agem de maneira harmônica, cada um exercendo a sua função, possibilitando uma ampla e complexa capacidade cognitiva, e que se vale de artifícios para otimizar a limitação que possui. O Sistema 1 funciona automaticamente e o Sistema 2 geralmente se encontra em modo de pouco esforço, utilizando pequena fração de sua capacidade. Na maior parte do tempo o primeiro sistema envia impressões e intuições para o segundo, sendo por este acatado com pouca ou nenhuma modificação.

Quando o Sistema 1 se verifica incapaz de realizar um processamento, a exemplo de dizer quantas letras tem a palavra jurisprudência ou quando há a necessidade de realizar uma observação mais atenta ao ambiente (encontrar uma pessoa, dentre uma multidão, que esteja utilizando fone de ouvido (exemplo dado acima)), o Sistema 2 é acionado para oferecer uma resposta que depende de uma maior profundidade cognitiva.

Diante disso, Kahneman arremata afirmando que na maior parte do tempo o que se pensa e o que se faz se origina do Sistema 1, mas o Sistema 2 assume o controle quando os processos ficam difíceis, sendo dele normalmente a última palavra (KAHNEMAN, 2012).

Tais percepções também foram alvo de investidas dos neurocientistas, que empreenderam esforços para compreender onde e como são feitas as atividades inconscientes e automáticas.

No final da década de 1970 o neurologista Michael Gazzaniga realizou um estudo em pessoas que tiveram os hemisférios do cérebro separados com o objetivo de reduzir ataques epiléticos. O propósito do estudo era analisar a forma com que as regiões do cérebro interagiam. Para tanto, durante os testes, inicialmente eram emitidos aos pacientes estímulos que somente poderiam ser interpretados por um hemisfério e depois outros estímulos que somente poderiam ser interpretados pelo outro hemisfério. Observou-se, então, que geralmente o paciente não reagia ao que era apresentado ao hemisfério direito. Para ele, nada lhe estava sendo mostrado. Porém, ao apresentar determinados comandos, tais como "caminhe", imediatamente a pessoa se levantava e saia da sala de teste. Ao serem questionados por qual razão eles haviam se levantado, logo davam uma resposta que era sensata, como por exemplo "vou para casa tomar refrigerante", mas que não fazia sentido serem dadas naquele momento.

O pesquisador, então, constatou que os pacientes possuíam uma grande capacidade de interpretar e encontrar justificativa para os comportamentos que não foram originados de maneira consciente, nem mesmo por iniciativa própria (GAZZANIGA, 1985). 
Com o desenvolvimento do estudo, Gazzaniga concluiu que muitos comportamentos diários são originados de processos cerebrais inconscientes e que a mente tem a capacidade de atribuir um sentido pós-fato a tais comportamentos de modo a construir uma narrativa coerente, mas que não é necessariamente verdadeira.

O estudo desse autor abriu portas para o desenvolvimento de pesquisa na área da neurociência para o desbravamento da mente inconsciente, que atualmente passa a ser provada a existência a partir de estudos de natureza neurológica e não somente por observação de comportamento.

John Bargh assinala que Freud já acreditava, de maneira dogmática, na existência de um "eu" separado e inconsciente que possuía qualidade inferior à consciência, responsável por compulsões sombrias e distorcidas. Porém, atualmente, com novos métodos disponíveis, é possível mudar o conceito da existência da mente inconsciente, deixando de ser uma crença dogmática para passar a ser uma constatação cientificamente comprovada, sendo certo que não se trata de um elemento separado e de qualidade inferior, visto que exames demonstram que as áreas do cérebro utilizadas para processos conscientes e inconscientes são as mesmas, entretanto, cada um segue um conjunto de regras próprio (BARGH, 2017).

Bargh dedicou toda a sua carreira para estudar a mente inconsciente e em seu livro publicado em 2017 intitulado de Before You Know It, tendo a versão brasileira recebido o título de O Cérebro Intuitivo, traz suas conclusões de quarenta anos de pesquisas e desenvolvimento de teses acerca desse mecanismo cerebral que é bem caracterizado pelos títulos das duas versões do livro. Nele, o pesquisador adverte que apesar da ideia da existência de processos inconscientes ser recebida de maneira cética por alguns, estes se revelam cotidianamente. Isso pode ser demonstrado através do fenômeno que ele denominou de Efeito Coquetel. Tal fenômeno ocorre quando um indivíduo está em um ambiente muito barulhento, com várias pessoas falando ao mesmo, a exemplo de uma festa, sem haver uma distinção de cada um dos sons que chegam aos ouvidos, no entanto, se alguém grita o seu nome o som é por ele percebido de maneira destacada aos demais. Esse simples fato corriqueiro revela que o cérebro realiza um filtro das informações recebidas através dos sentidos e somente permite que seja levado ao consciente o que é considerado importante. Esse mecanismo de filtragem ocorreu de maneira inteiramente automática, pois não houve a intenção de ativar esse filtro, bem como ocorreu de forma inconsciente, uma vez que o indivíduo não sabia que seu cérebro estava realizando tal feito (BARGH, 2017). Quando se estar inserido em um ambiente que 
possui muitos sons de fontes diferentes, não é raro que se passe a condensar todos eles como se fossem um único som, passe a encarar todos eles como se fossem somente um "barulho". No entanto, se dessa fusão surge um que é interessante ao indivíduo e ele chega de maneira destacada e clara à consciência, não se pode dizer que isso ocorreu por ele ter sido emitido de maneira mais alta e destoante dos demais, mas sim que decorreu em função de um processo interno de filtragem e classificação do que é importante.

$\mathrm{O}$ autor defende que a forma para melhor compreender o fenômeno do cérebro inconsciente é a partir da análise do tempo - presente, passado e futuro - afirmando que a mente existe nas três zonas ao mesmo tempo, não existindo ninguém que esteja apenas no presente, no passado ou no futuro.

O passado oculto é constituído pelas lições que foram adquiridas ao longo de vários anos e transmitidas pelas gerações pela genética com o intuito de garantir a sobrevivência da espécie. São protocolos automáticos que garantem instintos de defesa em face de perigos, a exemplo de ter um medo instintivo de aranhas e cobras ou o reflexo de rapidamente desviar de um objeto que estar vindo em sua direção.

O presente oculto é responsável pela capacidade do cérebro processar muito mais informações do que conscientemente acredita-se estar processando, possibilitando que sejam realizadas várias tarefas ao mesmo tempo (como já foi visto nas pesquisas de Kahneman). A descida de uma escadaria já conhecida dispensa, por exemplo, a atenção do indivíduo, sendo todo o trabalho de coordenação e sintonia dos músculos realizado de maneira inconsciente, sem nenhum esforço mental, garantindo margem de capacidade cognitiva para o desempenho de outras atividades.

As suas pesquisas de Bargh revelam que o presente oculto também afeta quase tudo o que é feito no dia-a-dia, tal como a escolha dos produtos que são comprados e a quantidade, as expressões faciais e os gestos ao conhecer uma pessoa (pois com a experiência de vida já se torna conhecidos os gestos e as expressões adequadas a essa ocasião), os palpites e as intuições (como também defende Kahneman nas duas obras acima referidas).

Esta afirmação demonstra que, apesar do inconsciente ser indispensável ao homem, possui uma rasa capacidade de análise do custo-benefício das ações, sendo influenciada pelos elementos ambientais e predisposições próprias do indivíduo.

O futuro oculto influencia a forma de agir do indivíduo de acordo com o que ele projeta o seu futuro, ou seja, a influência do inconsciente dependerá das metas e sonhos que 
ele tem, mas também de acordo com os medos, ansiedades e preocupações com o dia de amanhã.

Os desejos mais intensos podem determinar o que a pessoa gosta ou não e isso ocorre de maneira invisível. Bargh fundamenta essa constatação com um experimento de Sarah Hill e Kristina Durante, o qual demonstrou que mulheres que passam a acreditar que está na hora de encontrar um companheiro para ter um relacionamento duradouro, diminui a desaprovação a salões de bronzeamento artificial e pílulas para emagrecimento. Isso conclui que o mundo é interpretado de maneira que se harmoniza com os objetivos traçados (BARGH, 2017).

Esse experimento também demonstra que a mente inconsciente, apesar de ter uma baixa capacidade de analisar custo-benefício, como destacado acima, realiza atividades complexas a partir de uma vasta rede de informações armazenadas no cérebro, pois o desejo de encontrar um companheiro para uma relação duradoura não fez com que as mulheres simplesmente passassem a prestar mais atenção aos homens que cruzavam seu caminho, possivelmente fazendo deduções acerca do caráter e dos gostos somente pela sua fisionomia e sua vestimenta - ações essas também exercidas inconscientemente. Mas para além disso, inconscientemente, foram identificados instrumentos que eram potencialmente úteis para a consecução do objetivo traçado, aumentando em relação a eles uma predisposição ao uso ou, pelo menos, uma menor rejeição.

Essas associações foram amplamente exploradas na tentativa de compreender todos os seus desdobramentos e características para que fossem melhor compreendido aquilo que se encontrava oculto no próprio ser, mas que influencia diuturnamente as ações, pensamento, crenças e gostos.

Um dos experimentos realizados com esse intento foi criado por Lawrence Williams e Bargh. Já se sabia naquele momento, em decorrência de estudo realizado por John Bowlby, que os seres humanos fazem uma associação de sensação física de calor com sensação de segurança, e sensação de frio com sentimentos de insegurança (BOWLBY, 1969), pois durante a amamentação o filho sente o calor da mãe e passa a associá-lo a uma sensação de acalento e proteção. Esse calor físico é posteriormente associado ao calor social de confiança e cooperação.

A partir dessa premissa, Lawrence e Bargh conduziram o experimento pedindo que os participantes se acomodassem no laboratório e logo em seguida o experimentador pedia que eles segurassem seu copo de café enquanto organizava um formulário. Esse tempo em 
que os participantes seguravam o copo era em torno de dez segundo. Após devolvê-lo ao experimentador, era pedido que fosse lido um conjunto de cinco palavras que se dizia ser as características de uma pessoa. Ao final, deveriam dizer se gostavam ou não daquela pessoa.

O momento crítico do experimento era quando os participantes seguravam o copo de café, copo esse que era quente para metade dos participantes e gelado para a outra metade.

Como era esperado, as pessoas que haviam segurado o copo quente tenderam a gostar mais da pessoa descrita no formulário do que as que seguraram o copo frio (BARGH, WILLIAMS, 2008).

Indubitavelmente, os participantes não tinham ciência de que aquele fator externo - o copo de café quente - havia influenciado na sua escolha, o que revela que as decisões sofrem influência direta de elementos que estão abaixo da linha da consciência.

\section{IMPLICAÇÕES DO EFEITO PRIMING}

O conhecimento da existência de processos cognitivos inconscientes serviu de base para a identificação dos vários fenômenos que dele decorrem e é nesse esteio que passou a ser conhecido o efeito priming. Esse efeito, como demonstra o trabalho de revisão de José Carlos Schaidhauer et al. (2015), apesar de existir uma ampla gama de definições relativas ao seu mecanismo indutor, há uma convergência quanto a forma que ele se manifesta, podendo ser caracterizado como um fenômeno em que um estímulo influencia o comportamento subsequente sem que o indivíduo tenha consciência de que sua ação foi influenciada.

O trabalho pioneiro de Hebb (1950) conclui que os estímulos podem ser tanto internos como externos e que, permanecendo eletricamente ativos no neurônio, influencia na tomada de decisão no momento em que a pessoa é exposta a um estímulo subsequente por meio de uma associação neural. Simonson (2005) defende que o priming é o efeito de tornar uma memória mais acessível em decorrência de um estímulo prévio, o que tenderia a inclinar a decisão para uma escolha relacionada a essa memória pré-ativada. Não necessariamente essa memória seria acessada, o que significa dizer que não será sempre que houver uma préativação que o indivíduo fará a escolha baseada nela, no entanto, verifica-se que dentre uma amostra, há a verificação do aumento de decisões tomadas em direção ao estímulo.

A forma que o estímulo pode ser recepcionado pelo destinatário também é variada, o que aumenta as possibilidades de ocorrência do efeito. Estudos demonstram que a pré- 
ativação pode ocorrer de maneira subliminar ou supraliminar (BARGH; CHARTRAND, 2000). Subliminar significa dizer que não somente a associação entre o estímulo e a escolha seria inconsciente, mas o próprio estímulo seria recepcionado pela mente de modo que a consciência não tomaria conhecimento de sua existência, o que demonstra que mesmo elementos ambientais que passam despercebidos pela experiência subjetiva do indivíduo são processados pelo cérebro e possuem a capacidade de gerar influência.

Quanto aos supraliminares, há o reconhecimento consciente por parte do indivíduo de que ele foi exposto à informação, mas não há o reconhecimento que ela o induziu a uma escolha subsequente.

Trata-se, portanto, de um efeito que pode ocorrer de maneira espontânea e em qualquer ambiente, a qualquer momento e várias vezes ao dia, sendo taxativos Bargh e Chartrand (1999) ao afirmar que na maior parte do tempo as determinações das pessoas não decorrem de intenções conscientes, mas de processos mentais inconscientes desencadeados por características do ambiente.

Entretanto, diversos autores argumentam que o priming não tem o condão de criar uma vontade ou de mudar um comportamento sem que já exista uma predisposição para a tomada da decisão, sugerindo que o prime (estímulo que provoca o priming) ativa uma meta que estava adormecida, influenciando na tomada de decisões após sua ativação (BLAIR; LOCKE; STAJKOVIC, 2006). Dessa forma, o fenômeno não seria um aliciador de comportamento com capacidade de induzir uma ação que não correspondesse às vontades já existentes no indivíduo, sendo somente um impulsionador de comportamento nessa direção.

Todavia, ainda que exista tal conclusão, alguns estudos empíricos, além de demonstrar mais claramente o funcionamento do priming, dão indícios de que a sua atuação não se dá somente naqueles que possuem uma predisposição à realização da ação. E isso pode ser observado no tópico subsequente.

\subsection{O PRIMING NA PRÁTICA}

Em 1996 Bargh e outros colaboradores (BARGH; BURROWS, 1996) realizaram um experimento com alunos da Universidade de Nova York, com média vinte anos de idade, em que era pedido para eles formassem uma frase com quatro palavras a partir de um conjunto de cinco palavras a eles dadas, sob a alegação de que estavam fazendo um teste relacionado à 
proficiência da língua. Para um grupo, as palavras eram relacionadas ao estereótipo de uma pessoa idosa (Flórida (destino turístico popular entre os idosos americanos), velho (old), solitário, grisalho, egoísta, cuidadoso, entre outras) e para o segundo grupo as palavras tinham conotações variadas.

Após a criação das frases, era solicitado que os estudantes se dirigissem a outra sala que se encontrava no final do corredor, e enquanto eles faziam o percurso, os pesquisadores contabilizavam discretamente o tempo que levavam para fazê-lo. Esse, na verdade, era o ponto crítico do experimento: verificar se a exposição de palavras que fazem menção a um estereótipo poderia modificar as ações subsequentes no sentido de provocar uma mimetização. A constatação foi positiva quanto à hipótese. O grupo que recebeu o conjunto de palavras relacionadas à velhice levou mais tempo para andar pelo corredor em comparação ao grupo controle, ou seja, andaram mais lentamente.

Ao serem questionados se haviam percebido se as palavras possuíam uma temática comum, nenhum deles afirmou ter tido essa percepção.

A partir desse experimento, o psicólogo alemão Thomas Mussweiler criou um experimento para verificar se o priming também poderia ocorrer de maneira inversa, ou seja, uma ação influenciar as representações mentais. Para tanto, pediu que estudantes andassem por cinco minutos a uma cadência de trinta passos por minutos, o que representa um terço do ritmo normal. Após esse período, verificou-se que os participantes estavam com uma capacidade de reconhecer palavras relacionadas à velhice maior do que os do grupo controle (MUSSWEILLER, 2006).

Esses experimentos demonstram que a rede de associações de ideias é complexa e multifacetada e comprovam o que os outros autores aqui já referidos afirmaram: os processos inconscientes são responsáveis por várias ações ocorridas no dia-a-dia. Kahneman denomina essa espécie de associação como conexão ideomotora, uma vez que conecta representações mentais a movimentos motores. Contudo, adverte que esse efeito somente ocorre se o indivíduo tiver previamente uma percepção positiva sobre a temática. Isso quer dizer que os alunos que passaram a andar mais lentamente após a exposição das palavras relacionadas à velhice não possuíam uma aversão a idosos ou à velhice, pois acaso houvesse essa percepção negativa não teriam sido influenciados (KAHNEMAN, 2012).

Esses estudos demonstram que provavelmente não é acertada a conclusão tida por Blair et al, acima referido, ao afirmarem que somente agiria por influência de um prime quem 
já possuía o objetivo de realizar aquele ato, como se já fosse um objetivo traçado mentalmente. Não seria razoável pensar que jovens com idade média de vinte anos tivessem como uma meta iminente andar mais lentamente ou adotar características de pessoas idosas. A explicação de Kahneman é mais aceitável ao afirmar que o priming ocorre através de uma ativação associativa de ideias que possuem coerência entre si por elas já estarem mentalmente conectadas. Isso quer dizer que a condição para que um estímulo prévio influencie uma reação subsequente é a conexão dessas duas ideias na mente do indivíduo, não havendo a necessidade de ser um objetivo (KAHNEMAN, 2012).

Essa percepção é reforçada pelo estudo desenvolvido em 2009 envolvendo bebês de apenas dezoito meses de idade. Nele foram mostradas fotografias em que ficavam em evidência um objeto familiar a elas (bule de chá, um livro, um sapato) e ao fundo, em menor destaque, havia figuras de dois bonecos. Em um primeiro conjunto de fotos, os bonecos se encontravam juntos, um de frente para o outro e com um ombro encostado no ombro do outro. No segundo conjunto havia somente um boneco. No terceiro conjunto, ao invés de bonecos, havia um conjunto de caixotes. No quarto conjunto havia dois bonecos, um de costas para o outro.

Durante o experimento, o pesquisador apresentava oito fotografias pertencentes a um mesmo conjunto e nomeava o objeto que ficava em destaque, falando inclusive a sua cor e a sua finalidade, mas em nenhum momento se referia às figuras de segundo plano (os primes). Após isso, brincava um pouco com a criança e depois se afastava para pegar um conjunto de gravetos. Ao se aproximar novamente das crianças os gravetos eram derrubados de forma aparentemente acidental e o pesquisador assumia uma postura compatível com a situação, demonstrando que queria reaver aqueles gravetos caídos.

O resultado foi de que sessenta por cento $(60 \%)$ das crianças expostas ao primeiro conjunto de fotografias, cujo prime era os dois bonecos próximos um do outro, pegaram espontaneamente pelo menos um dos gravetos e o oferecia ao pesquisador dentro dos dez primeiros segundos após a queda. De outro modo, o percentual de bebês que foram expostos aos outros conjuntos de fotografia e que tiveram a mesma ação de ajuda espontânea foi de somente vinte por cento (20\%) (OVER, CARPENTER, 2009).

Dessa forma pode se concluir a partir desse estudo que, em primeiro, a percepção de que o priming para ocorrer necessita de uma meta previamente definida, há a demonstração, novamente, de ser uma percepção que não é de toda correta, uma vez que crianças de dezoito 
meses de idade estão aprendendo a falar e não é crível que estejam criando objetivos ou metas. É possível que elas, ao verem o exemplo daqueles que estão ao seu redor diariamente, a exemplo dos pais, estimulem-se a reproduzir um comportamento semelhante, prestando-se a serem mais solidárias, mas não o desejo prévio de agir com solidariedade. Em segundo, o estudo também demonstra que o priming pode ocorre em idades muito tenras, denunciando que decorre de um mecanismo mental que se desenvolve desde muito cedo, sendo portanto, uma constante em toda a vida humana.

Contudo, também demonstra que os primes podem ser sutis informações presentes no meio e facilmente implantados, ainda mais quando recordada ser possível a apresentação na forma subliminar, fazendo com que todo o processo de influência ocorra à revelia da consciência.

A sutileza dos primes se revela em todos os estudos empíricos, o que demonstra ser a uma característica central para a ocorrência do efeito de pré-ativação.

Tal característica é corroborada por um estudo publicado em 2010, realizado nas ruas de Paris. Nele os pesquisadores instruíram uma bela jovem de dezenove anos a abordar homens entre trinta e cinquenta anos para pedir informação sobre o melhor caminho para chegar a "Martin Street". Após a ajuda, cada um seguia o seu caminho, no entanto, dali aproximadamente trinta metros outra jovem, de mesma idade, abordava o mesmo homem e lhe informava que um grupo de quatro jovens de aspecto violento - que estavam próximos deles - havia roubado o seu celular e pedia que ele fosse até eles para solicitar a devolução. Somente vinte por cento (20\%) dos homens abordados aceitaram reivindicar o celular, visto se tratar de um cenário aparentemente perigoso.

No entanto, quando os pesquisadores realizaram um novo ciclo de abordagens, mantendo os mesmos padrões que o anterior, modificando somente o nome da rua, o percentual de homens que se disponibilizaram a solicitar o celular ao grupo de jovens aumentou para trinta e seis ponto sete por cento $(36,7 \%)$. O nome desta nova rua era "Valentine Street" (FICHER-LOKOU; GUÉGUEN, LAMY, 2010).

Como conclusão, os pesquisadores verificaram que apenas uma única palavra dita de maneira solta em um contexto foi capaz de ativar o senso de cavalheirismo dos homens abordados, aumentando em quase o dobro o número daqueles que se disponibilizaram a ajudar a jovem moça em face de quatro jovens aparentemente violentos. 
Uma hipótese levantada foi de que ainda existe uma regra social implícita de que os homens devem prestar ajuda à mulheres em uma situação de vulnerabilidade e que a palavra Valentine, que é fortemente associada à ideia de amor naquela cultura ${ }^{3}$, pré-ativou a necessidade da prestação de ajuda, encorajando esses homens, ainda que diante de uma situação de perigo.

Isso demonstra que apesar de não haver uma influência em cem por cento das pessoas que recebem o estímulo, há uma considerável modificação na amostra, bom como a influência se apresenta de maneira profunda e significativa, uma vez que uma única palavra foi capaz de predispor os abordados em assumir um risco físico, risco esse que não estavam dispostos a correr sem a influência - como demonstra o grupo controle.

Por fim, constatando-se a amplitude das consequências que o priming pode ter na vida em sociedade, um estudo publicado em 2008, demonstrou que o local de votação pode influenciar no voto. Esse estudo analisou o padrão de votos nas eleições no estado do Arizona, EUA, no ano 2000, e demonstrou que o candidato que possuía proposta de aumentar a verba para as escolas teve um número significativamente maior de votos nas urnas localizadas em escolas (BERGER; MEREDITH; WHEELER, 2008).

\section{AS IMPLICAÇÕES DO PRIMING NO DIREITO}

O que se verifica dos estudos aqui analisados é que o efeito priming é próprio do ser humano, sendo um fenômeno natural e que sempre existiu, no entanto, agora passa a ser conhecido. É certo que não se trata mais de descobertas tão recentes, uma vez que aqui foram tratados estudos que já completam setenta anos e desde lá vários são os trabalhos desenvolvidos, notadamente na área da neuropsicologia e da economia comportamental, porém, há uma manifesta escassez de abordagem no âmbito do Direito. Ainda que se tenham imprecisões quanto algumas definições, a exemplo do conhecimento do mecanismo indutor, a forma com que o priming se manifesta é praticamente uníssona, tornando-se um fenômeno conhecido e destacado entre os demais.

Exatamente em decorrência dessa identificação é que foi possível arquitetar tantos experimentos empíricos para analisar as suas mais diversas facetas e que possibilitaram

\footnotetext{
${ }^{3}$ No dia de São Valentin é comemorado o dia dos namorados na França.
} 
constatar que a sua capacidade de influenciar um comportamento por um estímulo prévio é amplo, que pode ser manipulado e que pode ser aplicado em diversos cenários.

No artigo já mencionado de Bargh, Chen e Burrows (1996), é enfática a afirmação que o efeito priming funciona como uma manipulação de ações futuras, o que significa dizer que desencadeia poderosamente ações subsequentes e é capaz de influenciar atitudes de consumo, comportamentos e decisões de maneira inconsciente. À medida que um fenômeno passa a ser mais conhecido, maior tona-se a possibilidade de seu manejo e vasta é a gama de estudos acerca desse fenômeno na área do marketing e da administração.

Robert Cialdini, em seu livro Pré-Suasão, que trata especificamente do efeito priming, dedica um capítulo somente para tratar do uso ético de tais técnicas, e nele revela que, para o seu arrepio, estudos globais demonstram que um elevado número de líderes empresariais experientes se mostram dispostos a adotarem condutas impróprias se elas se revelarem como instrumentos de aumento de ganhos, mesmo correndo o risco da mácula à reputação da empresa caso essas condutas sejam descobertas (CIALDINI, 2017), o que implicaria em perdas maiores que tais ganhos.

Ademais, os pesquisadores do estudo retro mencionado acerca do priming em bebês de dezoito meses afirmam que o estudo constata que os primes sociais podem influenciar o comportamento infantil e sugerem que mudanças sutis no ambiente social são suficientes para promover a mudança de comportamento (OVER; CARPENTER, 2009).

Por sua vez, o estudo conduzido sobre as eleições no estado do Arizona demonstra que o priming também pode estar presente em um dos pilares da democracia.

Diante desse cenário, verifica-se que existe um amplo horizonte a ser preenchido de análises que perpassam desde a validade dos negócios jurídicos, às técnicas de marketing, às propagandas políticas e análise acerca da influência indevida dos locais de votação e, em especial, na forma de fiscalização. Entretanto, pouco foi feito.

\section{CONSIDERAÇÕES FINAIS}

O Direito sempre anda um ou mais passos atrás dos fatos sociais, e não poderia ser diferente, pois, ainda que se tenha o intuito de se criar mecanismos jurídicos que se perpetuem no tempo, as mudanças fáticas alcançam um patamar que não é mais possível ser alcançado pela legislação vigente, havendo a necessidade de girar mais uma vez a máquina legislativa ou, em um meio tempo, a adaptação ou nova forma de interpretação da lei pela jurisprudência. 
Ocorre que o lapso que existente entre a mudança social e a adaptação do Direito pode custar vários danos de ordem social e individual, o que demanda da comunidade jurídica estudos constantes acerca das inovações para que o atraso não seja tão prejudicial.

O efeito priming se torna surpreendente pela crença comum de que é o consciente que detém de quase todo, senão todo, o controle das decisões, enquanto que os estudos revelam que se trata de uma atividade que tem ampla influência do inconsciente. Contudo, o priming - que decorre dos processos cerebrais inconscientes - pode ocorrer a qualquer momento, em qualquer cenário e em qualquer pessoa, bem como um estímulo pode se tornar um prime para um e não se tornar para outro, ou até mesmo, um único prime importar em influências diferentes para diferentes pessoas, o que, na prática poderia fazer com que a sua identificação passasse a ser uma tarefa muito difícil.

O número de experimentos empíricos que demonstram a possibilidade de criação intencional de estímulos, bem como a variedade de situações em que eles podem ser utilizados, deixam claros que não pode ignorado pelo Direito. Porém, em sentido contrário, é carente o número de estudos jurídicos a respeito da temática, mesmo sendo um tema que interessa aos mais diversos ramos, tais como direito civil, direito do consumidor, direito eleitoral, direito empresarial.

Os desafios parecem ser muitos, visto a necessidade de analisar as práticas já existentes que se valem dessas técnicas, a análise de verificar se a legislação existente é suficiente, bem como verificar como devem proceder as fiscalizações. Já não bastasse, é necessário verificar se é imperioso esperar uma definição uníssona das áreas competentes quanto ao mecanismo indutor do efeito priming para que, somente então, seja possível a criação de legislação regulatória.

O caminho parece ser longo e possivelmente se tornará cada vez maior na medida em que aumentarem os usos da pré-ativação de maneira intencional, mas é exatamente esse o motivo pelo qual existe a necessidade dos olhos do Direito também estarem voltados para esse tema, pois, nas palavras de Kahneman ao se referir ao estudo das eleições no Arizona, dentre centenas de votantes, somente alguns que ainda se encontram indecisos votarão diferente acerca de uma questão escolar se a sua urna estiver dentro de uma colégio, "mas basta uma pequena porcentagem para determinar o resultado de uma eleição" (KAHNEMAN, 2012, p. 74). 


\section{REFERÊNCIAS}

BARGH, John A. What have we been priming all these years? On the development, mechanisms, and ecology of nonconscious social behavior. European Journal of Social Psychology, Yale, v. 36, n. 2, p. 147-168, 2006. DOI: http://dx.doi.org/10.1002/ejsp.336. Disponível em: https://www.ncbi.nlm.nih.gov/pmc/articles/PMC2763379/. Acesso em 20 jun. 2020.

BARGH, John. O Cérebro Intuitivo: O processos inconscientes que nos levam a fazer o que fazemos. Tradutor: Paulo Geiger. Yale: Objetiva, 2017.

BARGH, John; BURROWS, Lara; CHEN, Mark. Automaticity of Social Behaviour: Direct Effects of Trait Construct and Stereotype Activation on Action. Journal of Personality and Social Psychology. v. 71, p. 230244, 1996.

BARGH, John; CHARTRAND, Tanya. Studying the Mind in the Middle: a practical guide to priming and automatic research. In H. Reis, C. Judd (Org.). Handbook of Research Methods in Psychology. New York: Cambridge University, 2000.

BARGH, John; CHARTRAND, Tanya. The Unbearable Automaticity of Being. American Psychologist. v.54, n. 7, p. 462-479, 1999. Doi: http://dx.doi.org/10.1037/0003-066X.54.7.462. Disponível em: https://doi.apa.org/search/display?id=36a2bc57-04d8-661d-8360ec15ec018fde\&recordId=2\&tab=PA\&page=1\&display=25\&sort=PublicationYearMSSort\%20desc,AuthorSort\% 20 asc \&sr=1. Acesso em 25 jun 2020.

BERGER, Jonah; MEREDITH, Marc; WHEELER, S. Christian. Contextual Priming: Where People Vote Affects How They Vote. PNAS, v. 105, n. 26, p. 8846-8849, 2008. DOI: https://doiorg.ez11.periodicos.capes.gov.br/10.1073/pnas.0711988105. Disponível em: https://wwwpnas.ez11.periodicos.capes.gov.br/content/105/26/8846. Acesso em: 25 maio 2020.

BLAIR, Eden; LOCKE, Edwin; STAJKOVIC, Alexander. A First Examination of the Relationships Between Primed Subconscious Goals, Assigned Conscious Goals, and Task performance. Journal of Apllied Psychology. v. 91, n. 5, p. 1172-1180, 2006. DOI: http://dx.doi.org/10.1037/0021-9010.91.5.1172. Disponível em: https://doi.apa.org/search/results?id=62ae85c9-164c-7849-65bd-d50168e4186d. Acesso em: 26 jun 2020.

BOWLBY, John. Attachment and Loss, v. I. Londres: The Hogarth Press, 1969.

CIALDINI, Robert B. Pré-Suasão: A influência começa antes mesmo da primeira palavra. Tradutor: Ivo Korytowski. Rio de Janeiro: Sextante, 2017.

FICHER-LOKOU, Jacques; GUÉGUEN, Nicolas; LAMY, Lubomi. Valentine Street Promotes Chivalrous Helping. Swiss Journal of Psychology. v. 69, n. 3, p. 169-172, 2010.

GAZZANIGA, Michael S. The Social Brain: Discovering the Network of the Mind. Nova York: Basic Books, 1985.

HEBB, Donald O. Organization of Behavior: A Neuropsychological Theory. Wiley Online Libary. Nova York, 1950. Disponível em: https://onlinelibrary.wiley.com/. Acesso em 22 jun. 2020.

JUNIOR PACHECO, José Carlos Schaidhauer; DAMACENA, Cláudio; BROZATTI, Rafael. Pré-ativação: o efeito priming nos estudos sobre o comportamento do consumidor. Estudos e Pesquisas em Psicologia. v. 15, n. 1, p. 284-309, 2015.

KAHNEMAN, Daniel. Rápido e Devagar: duas formas de pensar. Tradutor: Cássio de Arantes Leite. Rio de Janeiro: Objetiva, 2012. 
MANTOVANI, Danielle; GALVÃO, Fábio Henriqye Silva. Brand Priming Effect on Consumer' Risk Taking Behavior. Revista de Administração, v. 52, n. 1, p. 15-25, 2015. DOI:

http://dx.doi.org/10.1016/j.rausp.2016.09.002. Disponível em:

https://www.revistas.usp.br/rausp/article/view/125776/122669. Acesso em 01 jun 2020.

MUSSWEILER, Thomas. Doing Is for Thinking! Stereotype Activision by Stereotypic Movements.

Physichology Science. v. 17, n. 1, p. 17-21, 2006.

OVER, Harriet; CARPENTER, Malinda. Eighteen-Month-Old Infants Show Increased Helping Following Priming with Affiliation. Psychological Science. v. 20, p. 1189-1193, 2009. DOI: https://doi-

org.ez11.periodicos.capes.gov.br/10.1111\%2Fj.1467-9280.2009.02419.x. Disponível em: https://journalssagepub-com.ez11.periodicos.capes.gov.br/doi/10.1111/j.1467-9280.2009.02419.x. Acesso em 16 jun 2020.

RANGEL, Antonio; CHRISTOF, Koch; MILICA, Milosavljevic. Consumers can make decisions in as little as a third of a second. Judgment and Decision Making. Pasadema, v. 6, n. 6, p. 520-530, 2011.

SIMONSON, Itamar. In Defense of Consciousness: The Role of Conscious and Unconscious Inputs in Consumer Choice. Journal of Consumer Psycholoy. v. 15, n. 3, 211-217, 2005.

TVERSKY, Amos; KAHNEMAN, Daniel. Science, v. 185, p. 1124-1131, 1974. DOI:

10.1126/science.185.4157.1124. Disponível em: https://science.sciencemag.org/content/185/4157/1124. Acesso em: 01 jul 2020.

WILliAMS, Lawrence E.; BARGH, John A. Experiencing Physical Warmth Influences Interpersonal Warmth. Science, v. 322, n. 5901, p. 606-607, 2008. 